\title{
Synthesis, characterization and in vitro antimicrobial activity of some new Schiff bases and their complexes
}

\author{
Hossein Naeimi ${ }^{1}$, Zahra Sadat Nazifi ${ }^{1,2}$, Seyedeh Matin Amininezhad ${ }^{2}$ and Mehdi Amouheidari ${ }^{3}$
}

The Journal of Antibiotics (2013) 66, 687-689; doi:10.1038/ja.2013.73; published online 10 July 2013

Keywords: antimicrobial activity; diamine; Schiff base complexes; synthesis; 2-hydroxy-1-naphthaldehyde

Schiff bases are considered as a very important class of organic compounds because of their ability to form complexes with transition metal ions. ${ }^{1-3}$ Schiff bases were important class of ligands, such ligands and their metal complexes had a variety of applications including biological, clinical, analytical and industrial in addition to their important roles in catalysis and organic synthesis., ${ }^{4,5}$ These compounds have been used as drugs, and they possess a wide variety of antimicrobial activity against bacteria, fungi and certain type of tumors. ${ }^{6}$ Some drugs have increased activity when administered as metal chelates and inhibit the growth of tumors. ${ }^{7}$ It was seen that the biological active compounds become more bacteriostatic and carcinostatic upon chelation with metal ions, ${ }^{8}$ as well as their application for the preparation of ion selective electrodes. ${ }^{9}$

In this article, we describe the successful synthesis of novel Schiff bases and their complexes under mild reaction condition. The corresponding complexes were characterized by spectroscopic and physical data. The Schiff bases and their metal chelates were also tested for their in vitro antimicrobial activity using the macro-dilution (tube) broth method, determining the MIC leading to inhibition of microbial growth (National Committee for Clinical Laboratory Standards, NCCLS document M100-S12:NCCLS, Wayne, PA, 2000).

IR spectra were obtained as $\mathrm{KBr}$ pellets on a Perkin-Elmer 781 spectrophotometer and on an Impact 400 Nicolet FTIR spectrophotometer. ${ }^{1} \mathrm{H}$ NMR and ${ }^{13} \mathrm{C} \mathrm{NMR}$ were recorded in $\mathrm{CDCl}_{3}$ solvents on a Bruker DRX-400 spectrometer with tetramethylsilane as internal reference. Mass spectra were recorded on a Micro Mass UKLTD spectra. Melting points were obtained with a Yanagimoto micro melting point apparatus and are uncorrected. The purity determination of the substrates and reaction monitoring were accomplished by thin layer chromatography on silica-gel polygram SILG/UV 254 plates.

Typical procedure: Schiff base ligands were prepared by dissolving 2-hydroxy-1-naphthaldehyde (0.34 g, $2 \mathrm{mmol}$ ) and 1,2-phenylenediamine $(0.108 \mathrm{~g}, 1 \mathrm{mmol})$ in methanol with stirring in one portion. The stirring was continued to completion of the reaction. The progress of the reaction was monitored by thin layer chromatography. After the completion of the reaction, a colored substance was obtained. The solid product was filtered and washed with cold methanol. The crude product was purified by recrystallization from ethanol, and the pure Schiff base was obtained in high-to-excellent yields after leaving for the appropriate time. The Schiff bases are characterized by physical and spectroscopic data.

1,1' [1,2-Phenylenediylbis(nitrilomethylidine)] bis-(2-naphthol) (3a): orange solid, m.p. $=162-163{ }^{\circ} \mathrm{C}$; IR $(\mathrm{KBr}), \mathrm{v} / \mathrm{cm}^{-1}$ : 3373-3470 (stretch, OH, H bonded), 3046 (stretch, C-H, Aryl).1612 (stretch, $\mathrm{C}=\mathrm{N}), \quad 1487-1559 \quad(\mathrm{C}=\mathrm{C}, \mathrm{Ar}), 1169$ (stretch, C-O); ${ }^{1} \mathrm{H}$ NMR $\left(\mathrm{CDCl}_{3}, 400 \mathrm{MHz}\right) / \delta$ (p.p.m.): 15.45 (s, 2O-H, intramolecular hydrogen bonding), 9.39 (s, 2CH imine), $8.29(\mathrm{~d}, 2 \mathrm{H}, J=8.0 \mathrm{~Hz}) 7.73-7.61$ (dd, $4 \mathrm{H}, J=8.0 \mathrm{~Hz}, \mathrm{Ar}), 7.34(\mathrm{t}, 2 \mathrm{H}, J=8.0 \mathrm{~Hz}), 7.25(\mathrm{~d}, 2 \mathrm{H}, J=$ $4.0 \mathrm{~Hz}, \mathrm{Ar}$ ), 7.15 (t, $2 \mathrm{H}, J=4.0 \mathrm{~Hz}, \mathrm{Ar}$ ), 6.87 (t, $2 \mathrm{H}, J=8.0 \mathrm{~Hz}, \mathrm{Ar})$, $6.63(\mathrm{~d}, 2 \mathrm{H}) ;{ }^{13} \mathrm{C} \mathrm{NMR}\left(\mathrm{CDCl}_{3}, 100 \mathrm{MHz}\right) / \delta$ (p.p.m.): 170.02, $153.44,142.15,137.56,135.14,132.26,131.62,129,71,128.20,127.12$, 124.29, 122.55, 119.24, 114.37; anal. calcd. For C. H. N: 80.36(C), 5.30 $(\mathrm{H}), 6.69(\mathrm{~N})$; found: $80.31(\mathrm{C}), 6.67(\mathrm{H}), 6.78(\mathrm{~N})$.

Typical procedure: the appropriate quantity of $1,1^{\prime}[1,2$-Phenylenediylbis(nitrilo- methylidine)]bis-(2-naphthol) was dissolved in absolute methanol $(10 \mathrm{ml})$. To this solution was added a solution of $\mathrm{Cu}\left(\mathrm{CH}_{3} \mathrm{COO}\right)_{2}(0.24 \mathrm{~g}, 1 \mathrm{mmol})$ in absolute methanol. The mixture was stirred for $50{ }^{\circ} \mathrm{C}$ (Scheme 1). After the completion of the reaction, the precipitated complex was then filtered off, washed with cold ethanol and dried in a vacuum dessicator. After drying, the crude product was recrystallized from ethanol to give pure product. Schiff base complexes were obtained in excellent yield and short reaction times. These compounds were identified using physical and spectroscopic data.

1,1' [1,2-phenylenediylbis(nitrilomethylidine)]bis-2-naphtholatocop$\operatorname{per}(\mathrm{II})$ (4a): reddish solid, m.p. $=231-232{ }^{\circ} \mathrm{C}$; IR $(\mathrm{KBr}), \mathrm{v} / \mathrm{cm}^{-1}: 1600$ (stretch, $\mathrm{C}=\mathrm{N}), 1403-1534(\mathrm{C}=\mathrm{C}, \mathrm{Ar}), 1162$ (stretch, C-O); anal. calcd. For C. H. N: 71.99(C), $8.00(\mathrm{H}), 4.54(\mathrm{~N})$; found: $71.95(\mathrm{C})$, $8.50(\mathrm{H}), 4.53(\mathrm{~N})$; mass $(\mathrm{m} / \mathrm{e}): 479\left(\mathrm{M}^{+}+1,3\right), 478\left(\mathrm{M}^{+}, 12\right), 115$ (13), 416 (38), 76 (45), 83 (47), 65 (53), 63 (80), 107 (100). 
Antimicrobial studies: the antimicrobial activity of Schiff bases and their complexes were tested against the microorganisms. All the studied Schiff base complexes were screened for antimicrobial activity against the bacteria (Escherichia coli, Pseudomonas aeruginosa, Salmonella typhi and Staphylococcus aureus) using Ciprofloxacin as a standard, and against two fungi (Aspergillus niger and Aspergillus flavus) using fluconazole as a standard. Antimicrobial and antifungal efficiency of the synthesized Schiff base complexes are assessed using the macro-dilution (tube) broth method, determining the MIC leading to inhibition of microbial growth.

The Schiff base ligands are soluble in common organic solvents. These compounds have been prepared from the reaction of 2hydroxy-1-naphthaldehyde and various diamines in methanol solution at room temperature under mild conditions.

In this study, the corresponding products were achieved and characterized using spectroscopic and physical data. In the domain of material science, the main advantage in the use of Schiff base ligands relates to the availability of a free imino site that can be functionalized with a wide variety of appendages. In this reaction, a lot of useful double Schiff bases were afforded in high-to-excellent yields and short reaction times in methanol solution. The results of these reactions are summarized in Table 1.

In continuation of our investigation on the preparation of Schiff base complexes, we have synthesized Schiff base complexes by treating the above-mentioned Schiff base ligands with $\mathrm{Cu}\left(\mathrm{CH}_{3} \mathrm{COO}\right)_{2}$ at $50{ }^{\circ} \mathrm{C}$. The reaction of Schiff base ligands with the corresponding metal salt is represented in Scheme 1.

As shown in Scheme 1, when $1 \mathrm{~mol}$ of ligand reacts with $1 \mathrm{~mol}$ transition metal salt, the complex products can be prepared in methanol solution under mild conditions at $50^{\circ} \mathrm{C}$. The results of these reactions are summarized in Table 1. As it can be seen in this Table, three Schiff base complexes of metal (II) were afforded in high yields and short reaction times from the reaction of ligands with the transition metal salts. Most of the synthesized complexes are colored and are stable in air, soluble in DMSO, DMF, $\mathrm{MeOH}$ and EtOH. As it can be seen in this Table, the corresponding Schiff base complexes were obtained as solids, with melting points between 230 to $>300^{\circ} \mathrm{C}$, stable and colored.

The structures of obtained complexes were identified and characterized using spectroscopic data. The infrared spectrum gives enough information to elucidate the way of bonding of the ligands to the metal ions. The most characteristic vibrations are selected by comparing the IR spectra of the ligands with those of their metal complexes. The strong bands at $1600 \mathrm{~cm}^{-1}$ for free ligands are due to $v(\mathrm{C}=\mathrm{N})$ of azomethine vibration mode. This band shifts to lower region by about $10-15 \mathrm{~cm}^{-1}$ on chelation of ligand with the metal ions.

In vitro antimicrobial studies: the free ligands and their metal complexes were screened for their antimicrobial activity. The results are indicated in Table 1. As shown in this Table, the ligands 3a-c did not exhibit a significant antimicrobial activity.

In the present study, we carried out experiments to investigate the antimicrobial activity of Schiff base complexes against four bacterial strains (Escherichia coli, Pseudomonas aeruginosa, Salmonella typhi and Staphylococcus aureus) and two fungi (Aspergillus niger and Aspergillus flavus). Antimicrobial efficiency of the synthesized Schiff base complexes are assessed using the macro-dilution (tube) broth method, determining the MIC leading to inhibition of bacterial growth (National Committee for Clinical Laboratory Standards, NCCLS document M100-S12:NCCLS, Wayne, PA, 2000). Different concentrations of Schiff base complexes were prepared in sterilized MuellerHinton broth at final concentrations of $64,32,16,8,4,2$ and $1 \mathrm{mg} \mathrm{ml}^{-1}$. Suspension of bacteria in sterile peptone water was adjusted to $0.5 \mathrm{McF}$ arland. Then $1 \mathrm{ml}$ of suspension (0.5 McFarland) was added to each sample. The samples were kept in incubation at $37^{\circ} \mathrm{C}$ for $48 \mathrm{~h}$. After incubation, samples were taken from tubes with

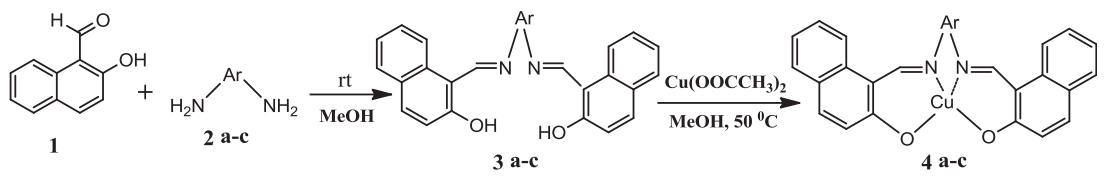

Scheme 1 Synthesis of Schiff bases (3a-c) and their complexes (4a-c).

Table 1 Antimicrobial and antifungal activity of the synthesized Schiff base complexes of copper

\begin{tabular}{|c|c|c|c|c|c|c|c|c|}
\hline \multirow[b]{3}{*}{ Compound } & \multirow[b]{3}{*}{ Time $(\min )$} & \multirow[b]{3}{*}{ Yield $(\%)$} & \multicolumn{6}{|c|}{ MIC Values $\left(m g m l^{-1}\right)$} \\
\hline & & & \multicolumn{3}{|c|}{ Bacteriab } & \multicolumn{3}{|c|}{ Fungt $^{\text {D }}$} \\
\hline & & & (a) & (b) & (c) & (d) & (e) & (f) \\
\hline $3 a$ & 45 & 92 & - & - & - & - & - & - \\
\hline $3 b$ & 30 & 89 & - & - & - & - & - & - \\
\hline $3 c$ & 100 & 72 & - & - & - & - & - & - \\
\hline $4 a$ & 75 & $82^{c}$ & 16 & 16 & 8 & 32 & 64 & 32 \\
\hline $4 b$ & 125 & $65^{c}$ & 2 & 32 & 4 & 8 & 8 & 16 \\
\hline $4 c$ & 150 & $70^{c}$ & 4 & 16 & 16 & 16 & 32 & 32 \\
\hline Ciprofloxacin ${ }^{d}$ & & & 0.0625 & 0.0625 & 0.125 & 0.0625 & & \\
\hline Fluconazole $^{\mathrm{d}}$ & & & & & & & 0.0625 & 0.0625 \\
\hline
\end{tabular}

alsolated yields.

cIsolated yields based on 2-hydroxy-1-naphthaldehyde.

b(a) Escherichia coli, (b) Pseudomonas aeruginosa, (c) Salmonella typhi (d) Staphylococcus aureus (e) Aspergillus niger (f) Aspergillus flavus.

${ }^{\mathrm{d}} \mathrm{Ciprofloxacin}$ and fluconazole were used as standard for antibacterial and antifungal activity, respectively. 
no visible growth of bacteria and then were applied on culture media for 24-72 h. Ciprofloxacin and fluconazole were used as standard for antibacterial and antifungal activity, respectively.

In the present wok, we have reported a mild, easy, clean and an efficient method for the synthesis of some novel Schiff base complexes of $\mathrm{Cu}(\mathrm{II})$ at $50^{\circ} \mathrm{C}$. The crude products were purified by recrystallization in ethanol, and the pure Schiff base complexes were obtained in high yields and short reaction times. Also the desired Schiff bases for the preparation of these complexes have been obtained through easy, simple method, from the reaction of 2-hydroxy-1-naphthaldehyde with various amines in methanol solution under mild condition. The free ligands and their metal complexes were screened for their antimicrobial activity. The results indicated that although the ligand did not exhibit a significant antimicrobial activity, the related complexes were shown higher efficiency against some microorganisms under experimental conditions.

\section{ACKNOWLEDGEMENTS}

The authors are grateful to Shahreza University and University of Kashan for supporting this work by Grant No. 159148/9.
1 Ziyad, A., Tahaa, A. M., Ajlounia, W. A. M. \& Abeer, A. Al-Ghzawia, syntheses, characterization, biological activities and photophysical properties of lanthanides complexes with a tetradentate Schiff base ligand. Spectro. Chim. Acta 81, 570-577 (2011).

2 You, Z. L., Tang, L. L. \& Zhu, H. L. A dinuclear oxygen-bridged Schiff base iron(III) complex derived from N,N'-bis-(2-hydroxybenzylidene)- 1,2-diaminopropane. Acta. Crystallogr. 61, 36-38 (2005).

3 Vigato, P. A. \& Tamburini, S. The challenge of cyclic and acyclic Schiff bases and related derivatives. Coord. Chem. Rev. 248, 1717-2128 (2004).

4 Jayabalakrishnan, C. \& Natarajan, K. Ruthenium (II) carbonyl complexes with tridentate Schiff bases and their antibacterial activity. Trans. Met. Chem. 27, 75-79 (2002).

5 Sharghi, H. \& Nasseri, M. A. Schiff-base metal (II) complexes as new catalysts in the efficient, mild and regioselective conversion of 1,2-epoxyethanes to 2-hydroxyethyl thiocyanates with ammonium thiocyanate.. Bull. Chem. Soc. Jpn. 76, 137-142 (2003).

6 Keskioglu, E., Gündüzalp, A. B., Cete, S., Hamurcu, F. \& Erk, B. $\mathrm{Cr}(I I I), F e(I I I)$ and Co(III) complexes of tetradentate (ONNO) Schiff base ligands: Synthesis, characterization, properties and biological activity. Spectro. Chim. Acta A 70, 634-640 (2008).

7 Wu, J. Z. \& Yuan, L. Synthesis and DNA interaction studies of a binuclear ruthenium(II) complex with 2,9-bis(2-imidazo[4,5-f][1,10]phenanthroline)-1,10-phenanthroline as bridging and intercalating ligand. J. Inorg. Biochem. 98, 41-45 (2004).

8 Chohan, Z. H., Perrvez, H. \& Kausar, S. Synthesis and characterization of antibacterial $\mathrm{Co}(\mathrm{II}), \mathrm{Cu}(\mathrm{II}), \mathrm{Ni}(\mathrm{II})$, and $\mathrm{Zn}(\mathrm{II})$ complexes of acylhydrazine derived pyrrolyl compounds. Synth. React. Inorg. Met. -Org. Chem. 32, 529-543 (2002).

9 Shamsipur, M., Ghiasvand, A. R., Sharghi, H. \& Naeimi, H. Solid phase extraction of ultra trace copper (II) using octadecyl silica membrane disks modified by a naphtholderivative Schiff's base. Anal. Chim. Acta 408, 271-277 (2000). 